\title{
TU/e EmonOWEN

\section{Dependence of computed copolymer reactivity ratios on the calculation method. I. Effect of experimental setup}

\section{Citation for published version (APA):}

Hautus, F. L. M., Linssen, H. N., \& German, A. L. (1984). Dependence of computed copolymer reactivity ratios on the calculation method. I. Effect of experimental setup. Journal of Polymer Science, Polymer Chemistry Edition, 22(11, Pt. 2), 3487-3498. https://doi.org/10.1002/pol.1984.170221161

DOI:

10.1002/pol.1984.170221161

Document status and date:

Published: 01/01/1984

\section{Document Version:}

Publisher's PDF, also known as Version of Record (includes final page, issue and volume numbers)

\section{Please check the document version of this publication:}

- A submitted manuscript is the version of the article upon submission and before peer-review. There can be important differences between the submitted version and the official published version of record. People interested in the research are advised to contact the author for the final version of the publication, or visit the $\mathrm{DOI}$ to the publisher's website.

- The final author version and the galley proof are versions of the publication after peer review.

- The final published version features the final layout of the paper including the volume, issue and page numbers.

Link to publication

\section{General rights}

Copyright and moral rights for the publications made accessible in the public portal are retained by the authors and/or other copyright owners and it is a condition of accessing publications that users recognise and abide by the legal requirements associated with these rights.

- Users may download and print one copy of any publication from the public portal for the purpose of private study or research.

- You may not further distribute the material or use it for any profit-making activity or commercial gain

- You may freely distribute the URL identifying the publication in the public portal.

If the publication is distributed under the terms of Article 25fa of the Dutch Copyright Act, indicated by the "Taverne" license above, please follow below link for the End User Agreement:

www.tue.nl/taverne

Take down policy

If you believe that this document breaches copyright please contact us at:

openaccess@tue.nl

providing details and we will investigate your claim. 


\title{
Dependence of Computed Copolymer Reactivity Ratios on the Calculation Method. I. Effect of Experimental Setup
}

\author{
F. L. M. HAUTUS, H. N. LINSSEN, ${ }^{*}$ and A. L. GERMAN ${ }^{\dagger}{ }^{\prime}$ Laboratory of \\ Polymer Chemistry, Eindhoven, University of Technology, \\ Eindhoven, The Netherlands
}

\begin{abstract}
Synopsis
Five calculation methods for estimating reactivity ratios are compared. Two of these methods are only valid at low conversion, two methods are assumed to be valid up to high conversion, and the fifth method is the integrated form of the copolymer equation. Data were simulated for selected couples of $r$-values and two conversion levels. The data were randomly disturbed by normal error with mean zero. As (the) monomer feed ratio(s) will be drifting during the course of reaction, the influence of an approximated monomer feed ratio on the $r$-values calculated was also examined. When conversion is low, all methods give estimates with low precision. High conversion results in larger precision, however, for several methods bias appears. For calculation methods that need information about an approximated monomer feed ratio, the influence of this approximation appears to be rather important especially if the $r$ values are dissimilar or conversion is high.
\end{abstract}

\section{INTRODUCTION}

In 1944 the simple (differential) copolymer equation was derived by Alfrey and Goldfinger ${ }^{1}$ and Mayo and Lewis. ${ }^{2}$ A number of techniques for computing reactivity ratios have since been developed, based on the differential equation and on data consisting of the initial or average monomer feed ratio and the resulting copolymer composition.

There are three factors that introduce systematic errors in the calculated reactivity ratios:

(1) The ratio of the instantaneous monomer consumption is approximated by the copolymer composition.

(2) Most copolymerization reactions inevitably show a drift of the molar feed ratio and so the differential copolymerization equation is only approximately valid.

(3) The reactivity ratios are computed, using simple least-squares methods, thereby neglecting the error in the so-called independent variable.

Because of factors (1) and (2) the differential copolymerization equation is only approximately valid. The advance of using a computer allows the use of the integrated copolymer equation such that the systematic error due to these two factors can be eliminated.

\footnotetext{
' Department of Mathematics, Eindhoven, University of Technology, Eindhoven, The Netherlands.

${ }^{+}$Correspondence should be addressed to A.L. German and H.N. Linssen.
} 
Patino-Leal et al. ${ }^{3}$ and Van der Meer et al..$^{4}$ gave examples of significant systematic errors due to factor (3). They also described a calculation method for coping inadequately with the error structure of the observations. ${ }^{4}$ As this method is intricate and difficult to implement, at least relative to the methods based on the differential equation, it seems worthwhile to investigate in which cases it yields significantly better results.

Proper examination of the various methods requires the experimental data to be generated by simulation because only in that case can error structure and true $r$-values be known exactly.

A number of representative $r$-values are chosen. For each couple of $r$-values true values of the monomer feed ratio and corresponding conversion based on the total number of moles reacted are computed with the aid of the integrated copolymer equation.

In experimental practice, conversion and monomer feed ratio are computed from observed gas-liquid chromatographic peak areas. These observations are now simulated by disturbing the ideal GLC peak areas by random error. Finally, estimated $r$-values are calculated for each method. To obtain a sample of calculated $r$-values simulation is repeated several times for each method. These samples are compared according to several criteria.

In the first part of this paper five well-known calculation methods are compared. Four of these methods are based on the differential equation and employ simple least-squares methods. The fifth method is based on the integrated copolymer equation and considers errors both in conversion and in monomer feed ratio.

The second part of the present paper deals with calculation methods that require information about an "average" monomer feed ratio. This "average" monomer feed ratio is approximated either by averaging initial and final monomer feed ratio or simply by the initial monomer feed ratio. The results are compared with respect to bias. Also, $r$-values are recalculated from published data to show the impact of using approximations for the "average" monomer feed ratio.

\section{SUMMARY OF THE CALCULATION PROCEDURES USED}

For the calculation of $r$-values Alfrey and Mayo derived the simple differential copolymer equation

$$
\frac{d\left[\mathrm{M}_{1}\right]}{d\left[\mathrm{M}_{2}\right]}=\frac{r_{1} q+1}{r_{2} / q+1}
$$

where $d\left[\mathrm{M}_{1}\right] / d\left[\mathrm{M}_{2}\right]$ is the ratio of the instantaneous rates of consumption of the monomers by chain propagation and $q=\left[\mathrm{M}_{1}\right] /\left[\mathrm{M}_{2}\right]$ is the molar ratio of the instantaneous monomer feed concentrations. The ratio of differentials $d\left[\mathrm{M}_{1}\right] / d\left[\mathrm{M}_{2}\right]$ cannot be measured directly and is approximated by

$$
\frac{d\left[\mathrm{M}_{1}\right]}{d\left[\mathrm{M}_{2}\right]} \approx \frac{\Delta \mathrm{M}_{1}}{\Delta \mathrm{M}_{2}}
$$

where $\Delta M_{1} / \Delta M_{2}$ is the copolymer composition. 
However, as the reaction proceeds, the monomer feed composition generally will be drifting. The average monomer feed ratio $\left(q_{\mathrm{A}}\right)$ is introduced by

$$
q_{\mathrm{A}}=\left(q_{0}+q_{\mathrm{F}}\right) / 2
$$

where $q_{0}$ and $q_{\mathrm{F}}$ are the initial and final monomer feed ratios.

The first and most simple method of calculating $r$-values is based on the equation

$$
\frac{\Delta \mathrm{M}_{1}}{\Delta \mathrm{M}_{2}}=\frac{r_{1} q_{\mathrm{A}}+1}{r_{2} / q_{\mathrm{A}}+1}
$$

and employs non-linear least-squares. In this paper it is referred to as the ALMA (Alfrey-Mayo) method.

The Alfrey-Mayo equation can be linearized ${ }^{5}$ by introduction of

$$
G \equiv \frac{q_{\mathrm{A}}\left(\Delta \mathrm{M}_{1} / \Delta \mathrm{M}_{2}-1\right)}{\Delta \mathrm{M}_{1} / \Delta \mathrm{M}_{2}} \quad \text { and } \quad F \equiv \frac{q_{\AA}^{2}}{\Delta \mathrm{M}_{1} / \Delta \mathrm{M}_{2}}
$$

to yield

$$
G=r_{1} F-r_{2}
$$

Such a transformation has an unfortunate consequence: the equation is no longer symmetrical with respect to the definition of which monomer is 1 and which is 2 , and reindexing can lead to two sets of computed $r$-values. Tüdös et al. $^{6}$ symmetrized eq. (4) by introduction of

$$
\eta=G /(\alpha+F) \text { and } \xi=F /(\alpha+F)
$$

where $\alpha$ is the parameter of symmetrization defined as

$$
\alpha=\sqrt{F_{\min } \cdot \overline{F_{\max }}}
$$

Equation (4) can now be rearranged to

$$
\eta=\left(r_{1}+\frac{r_{2}}{\alpha}\right) \xi-r_{2} / \alpha
$$

The solution of this linear least-squares problem is given by Kelen et al. ${ }^{7}$ This is the second method surveyed in our comparison and is referred to as the KETL (Kelen-Tüdös low conversion) method.

Both methods described above are applicable only in the case of low conversion or azeotropic copolymerization $\left(q_{0} \approx q_{\mathrm{F}}\right)$.

Kelen et al. ${ }^{7}$ modified KETL for high conversion by redefining $F$ and $G$ as follows:

$$
F=\frac{\Delta \mathrm{M}_{1}}{\Delta \mathrm{M}_{2}} *\left(\frac{\log z_{2}}{\log z_{1}}\right)^{2} \quad \text { and } \quad G=\left(\frac{\Delta \mathrm{M}_{1}}{\Delta \mathrm{M}_{2}}-1\right) \frac{\log z_{2}}{\log z_{1}}
$$


where

$$
z_{1}=\frac{\mathbf{M}_{1 \mathrm{~F}}}{\mathbf{M}_{10}} \quad \text { and } \quad z_{2}=\frac{\mathbf{M}_{2 \mathrm{~F}}}{\mathbf{M}_{20}}
$$

$M_{10}, M_{1 F}$ and $M_{20}, M_{2 F}$ represent the initial and final concentrations of monomer 1 and monomer 2, respectively.

Estimates for $r_{1}$ and $r_{2}$ can then be obtained by using linear least-squares based on eq. (5). This method is claimed to be applicable to high conversion and is referred to as the KETH (Kelen-Tüdös high conversion) method.

Another way of approaching eq. (1) was presented by Watts et al. ${ }^{8}$ They transformed the Alfrey-Mayo equation into

$$
\frac{d \ln \mathrm{M}_{1}}{d \ln \mathrm{M}_{2}}=\frac{r_{1} q+1}{r_{2}+q}
$$

For many copolymerizations $d \ln \mathbf{M}_{1} / d \ln \mathbf{M}_{2}$ appears to be rather constant within a kinetic experiment even up to high conversion. This phenomenon was used by defining

$$
\beta=\frac{\Delta \ln \mathrm{M}_{1}}{\Delta \ln \mathrm{M}_{2}} \approx \mathrm{constant}
$$

The following equation is then assumed to be valid:

$$
\beta=\frac{r_{1} q_{\mathrm{A}}+1}{r_{2}+q_{\mathrm{A}}}
$$

$\beta$ can now be estimated for each experiment by simple linear regression of $\Delta \ln \mathrm{M}_{1}$ or $\Delta \ln \mathrm{M}_{2}$ and vice versa. ${ }^{8}$ The set $\beta$ 's and $q_{\mathrm{A}}$ 's obtained in this way can be used to calculate the $r$-values employing a non-linear leastsquares method based on eq. (7). This fourth procedure will be referred to as the WLS (Watts, Linssen, and Schrijver) method.

The fifth method presently investigated is based on the integrated form of the Alfrey-Mayo equation. Integration yields

$$
z_{2}=\left(\frac{q}{q 0}\right)^{-1-x_{2}}\left(\frac{x_{2} q-x_{1}}{x_{2} q_{0}-x_{1}}\right)^{1+x_{1}+x_{2}}
$$

where $x_{1}=1 /\left(r_{1}-1\right), x_{2}=1 /\left(r_{2}-1\right)$, and $z_{2}=\mathrm{M}_{2} / \mathbf{M}_{20}$.

Van der Meer et al. ${ }^{4}$ used a non-linear least-squares algorithm for considering errors in both variables, as developed by Linssen, ${ }^{9}$ for the estimation of $r_{1}$ and $r_{2}$. This method of estimating $r$-values will be referred to as the VLG (Van der Meer, Linssen, and German) method.

\section{SIMULATION AND COMPARISON}

The simulation is based on the presumption that only initial and final reaction mixtures, containing two monomers and a solvent, are repetitively analyzed by GLC. These primary experimental data allow all necessary 
variables to be obtained (copolymer composition, monomer feed ratio, conversion, etc.). The solvent peak is used as internal standard and thus is to be considered as one of the primary experimental data.

The integrated form of the Alfrey-Mayo equation (8) is based on the conversion of one of the monomers. For simulating purposes this form is not recommended. When the conversion of one of the monomers is selected the conversion of the other monomer may attain extremely high or low values especially if the $r$-values are very dissimilar. Therefore, a measure of conversion based on the total number of moles reacted is introduced here. This "total conversion" is defined as

$$
\text { Conv }_{\mathrm{t}}=\frac{\mathbf{M}_{10}-\mathbf{M}_{1}+\mathbf{M}_{20}-\mathbf{M}_{2}}{\mathbf{M}_{10}+\mathbf{M}_{20}}=1-z_{\mathrm{t}}
$$

where $\mathbf{M}_{10}$ and $\mathbf{M}_{20}$ are the initial number of moles of $\mathbf{M}_{1}$ and $\mathbf{M}_{2}$, respectively, and $\mathbf{M}_{1}$ and $\mathbf{M}_{2}$ are the instantaneous number of moles of $\mathbf{M}_{1}$ and $\mathrm{M}_{2}$, respectively.

The equation used to simulate the "experiments" is based on this "total conversion" and can be derived by combining eqs. (8) and (9):

$$
z_{\mathrm{t}}=\frac{(q+1)}{\left(q_{0}+1\right)} \cdot\left(\frac{q}{q_{0}}\right)^{-1-x_{2}}\left(\frac{x_{2} q-x_{1}}{x_{2} q_{0}-x_{1}}\right)^{1+x_{1}+x_{2}}
$$

For selected couples of $r$-values, 10 "experiments" with initial monomer feed ratios $\left(q_{0}\right)$ varying from 5 with steps of 0.5 down to 0.5 are chosen. Within each set of "experiments" the "total conversion" is selected (20\% or $40 \%)$ and the corresponding final monomer feed ratios $\left(q_{\mathrm{F}}\right)$ are computed by means of the adapted integrated copolymer equation (10). Then, for each "experiment" ideal GLC peak areas are generated for the initial and final observations (realistic values are chosen for the areas of solvent and initial $\mathrm{M}_{2}$ peak). These ideal peak areas are now randomly disturbed by a normal error with mean zero and standard deviation of $1 / \sqrt{15} \%$. This standard deviation is equal to the standard deviation of the average of 15 random disturbances each with standard deviation of $1 \%$.

From these disturbed areas the monomer feed ratio, degree of conversion of monomers 1 and 2, copolymer composition, etc., are computed, and these data are used to estimate the $r$-values when applying each of the five calculation methods investigated in this paper. For VLG additional information is needed concerning the error structure of the observation. ${ }^{4}$ In this way each method yields 50 estimates for $r_{1}-r_{2}$ pairs.

There are a number of ways to compare the performances of the methods. Two useful quantitative measures are the "mean distance":

$$
\mathrm{MD}=\sum_{p=1}^{50} \sqrt{\left(r_{i 1}-R_{1}\right)^{2}+\left(r_{i 2}-R_{2}\right)^{2}} / 50
$$

and the "mean relative distance":

$$
\mathrm{MRD}=\sum_{p=1}^{50} \sqrt{\left(1-r_{i 1} / R_{1}\right)^{2}+\left(1-r_{i 2} / R_{2}\right)^{2}} / 50
$$


where $\left(r_{i 1}, r_{i 2}\right)$ represent the estimated $r$-values and $R_{1}$ and $R_{2}$ the corresponding true values. In Table I the MRD's are displayed for all cases studied. Displaying MD would give similar results.

The results of the simulation can also be visually represented by "approximately smallest $50 \%$ frequency regions." These are (approximately) the smallest regions that contain $50 \%$ of the pairs of estimated $r$-values and are ellipsoids given by the following equation in the $r_{1}-r_{2}$ plane:

$$
\left(r_{1}-\bar{r}_{1}, r_{2}-\bar{r}_{2}\right) S^{-1}\left(\begin{array}{l}
r_{1}-\bar{r}_{1} \\
r_{2}-\bar{r}_{2}
\end{array}\right)=\chi_{2}^{2}(.50)
$$

where $\bar{r}_{1}$ and $\bar{r}_{2}$ denote the average value of the reactivity ratios, $S$ denotes the estimated covariance matrix, and $\chi_{2}^{2}(.50)$ the $50 \%$ point of the chi-square distribution on two degrees of freedom.

In Figure 1 all 50 estimated pairs of $r$-values for all methods are displayed, together with the corresponding 50\% regions for a selected case. In Figures 2 and 3 these $50 \%$ regions are displayed for all cases.

In the sequel the following terminology will be used: when the area of its $50 \%$ region is small (large) the method under consideration will be said to have a large (small) "precision." When the distance between the center of the 50\% region and the pair of true values of $r_{1}$ and $r_{2}$ is small (large) the method will be said to have a small (large) "bias." Small precision or high bias will give rise to a large mean distance $\mathrm{MD}$ and large mean relative distance MRD.

TABLE I

Mean Relative Distance (MRD) for All Methods

\begin{tabular}{|c|c|c|c|c|c|c|c|}
\hline$R_{1}$ & $R_{2}$ & $\begin{array}{c}\text { Total } \\
\text { conversion } \\
(\%)\end{array}$ & VLG & WLS & ALMA & KETL & KETH \\
\hline \multirow[t]{2}{*}{0.20} & 10 & 20 & 0.090 & 0.120 & 0.213 & 0.242 & 0.179 \\
\hline & & 40 & 0.023 & 0.087 & 0.608 & 0.617 & 0.076 \\
\hline \multirow[t]{2}{*}{0.35} & 0.20 & 20 & 0.057 & 0.064 & 0.070 & 0.060 & 0.057 \\
\hline & & 40 & 0.024 & 0.030 & 0.113 & 0.089 & 0.028 \\
\hline \multirow[t]{2}{*}{0.45} & 0.02 & 20 & 0.415 & 0.531 & 0.470 & 0.450 & 0.442 \\
\hline & & 40 & 0.166 & 0.414 & 0.384 & 0.385 & 0.231 \\
\hline \multirow[t]{2}{*}{0.60} & 0.550 & 20 & 0.034 & 0.033 & 0.056 & 0.036 & 0.036 \\
\hline & & 40 & 0.014 & 0.014 & 0.041 & 0.029 & 0.015 \\
\hline \multirow[t]{2}{*}{0.90} & 0.30 & 20 & 0.043 & 0.043 & 0.091 & 0.047 & 0.047 \\
\hline & & 40 & 0.018 & 0.019 & 0.039 & 0.023 & 0.021 \\
\hline \multirow[t]{2}{*}{2.0} & 0.10 & 20 & 0.157 & 0.171 & 0.374 & 0.171 & 0.172 \\
\hline & & 40 & 0.056 & 0.128 & 0.147 & 0.072 & 0.077 \\
\hline \multirow[t]{2}{*}{4.0} & 0.70 & 20 & 0.057 & 0.068 & 0.330 & 0.073 & 0.074 \\
\hline & & 40 & 0.022 & 0.032 & 0.122 & 0.034 & 0.031 \\
\hline \multirow[t]{2}{*}{10} & 0.30 & 20 & 0.166 & 0.243 & 1.187 & 0.309 & 0.324 \\
\hline & & 40 & 0.050 & 0.157 & 0.536 & 0.293 & 0.100 \\
\hline
\end{tabular}




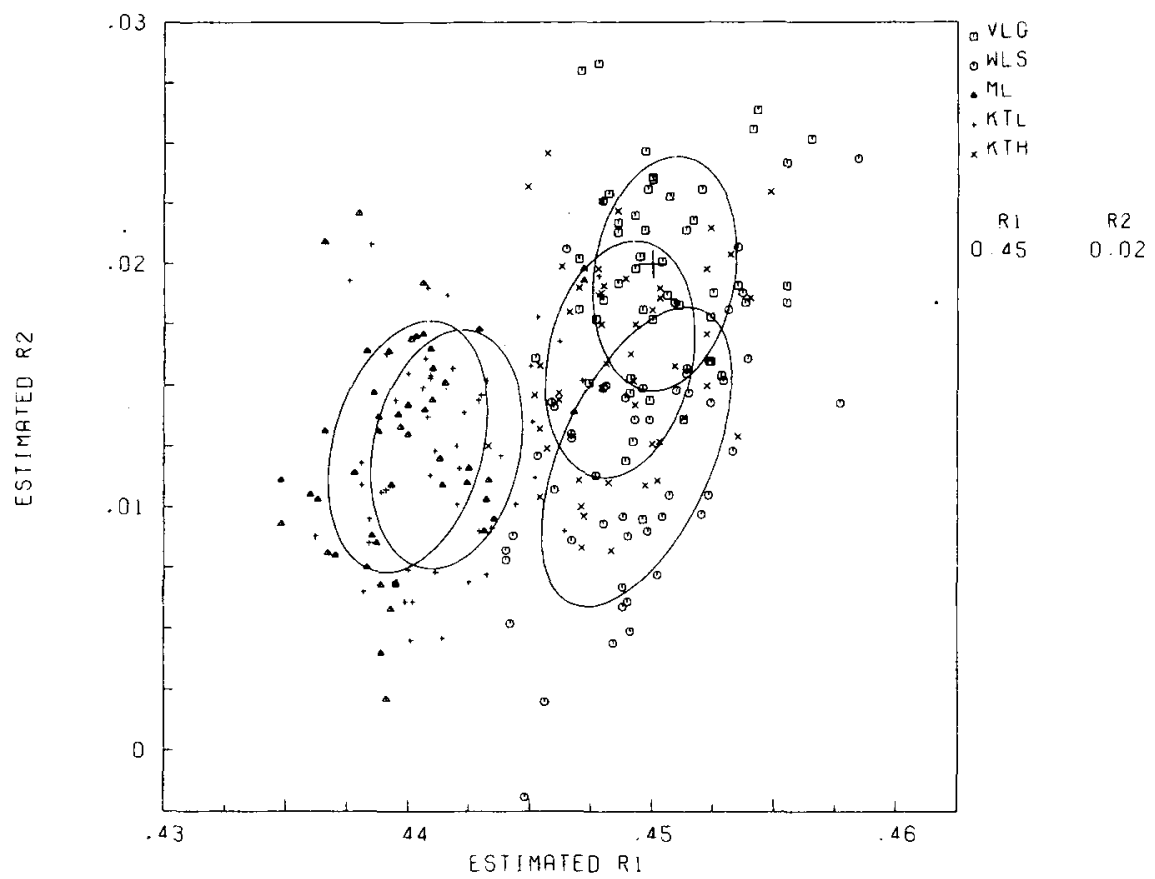

Fig. 1. Fifty simulated estimates for $r_{1}$ and $r_{2}$ for each method and associated approximately smallest $50 \%$ frequency regions.

Figures 2 and 3 and Table I allow the following conclusions to be drawn:

(1) ALMA and KETL are almost similar with respect to bias, but ALMA has a comparatively small precision.

(2) Inspection of Table I and Figures 2 and 3 suggests that KETH is indeed an improvement of KETL. There are, however, a few exceptions especially if conversion is $20 \%$.

(3) In some cases WLS is superior to KETH, and in other cases the reverse is true. There seems to be no general rule for this phenomenon.

(4) Bias seems to increase as conversion increases. However, small conversion is not recommended because precision will become small.

(5) The one method that is definitely superior to the four others is VLG, not primarily because of its precision, but because of its almost zero bias.

The excellent performance of VLG can be asscribed to two factors:

- it is based on the integrated copolymer equation and consequently does not suffer from the systematic errors, due to linearization, and

- it takes fully into account the error structure of the observations.

In Table $I$ and Figures 2 and 3 it is clearly shown for all approximate calculation methods that increasing conversion results in increasing precision, however, at the expense of a simultaneously increasing bias. This bias is introduced by the drift in the monomer feed ratio, which is a function of conversion and $r$-values. Therefore, comparison of calculation methods without taking into account conversion as reported by McFarlane et al. ${ }^{10}$ may give an incomplete impression about the validity of these methods. Besides, if $r$-values are estimated, the experimenter has to choose a certain finite conversion, as the instantaneous ratio of monomer consumption rates $d \mathrm{M}_{1} / d \mathrm{M}_{2}$ cannot be estimated directly. So the influence of the conversion 

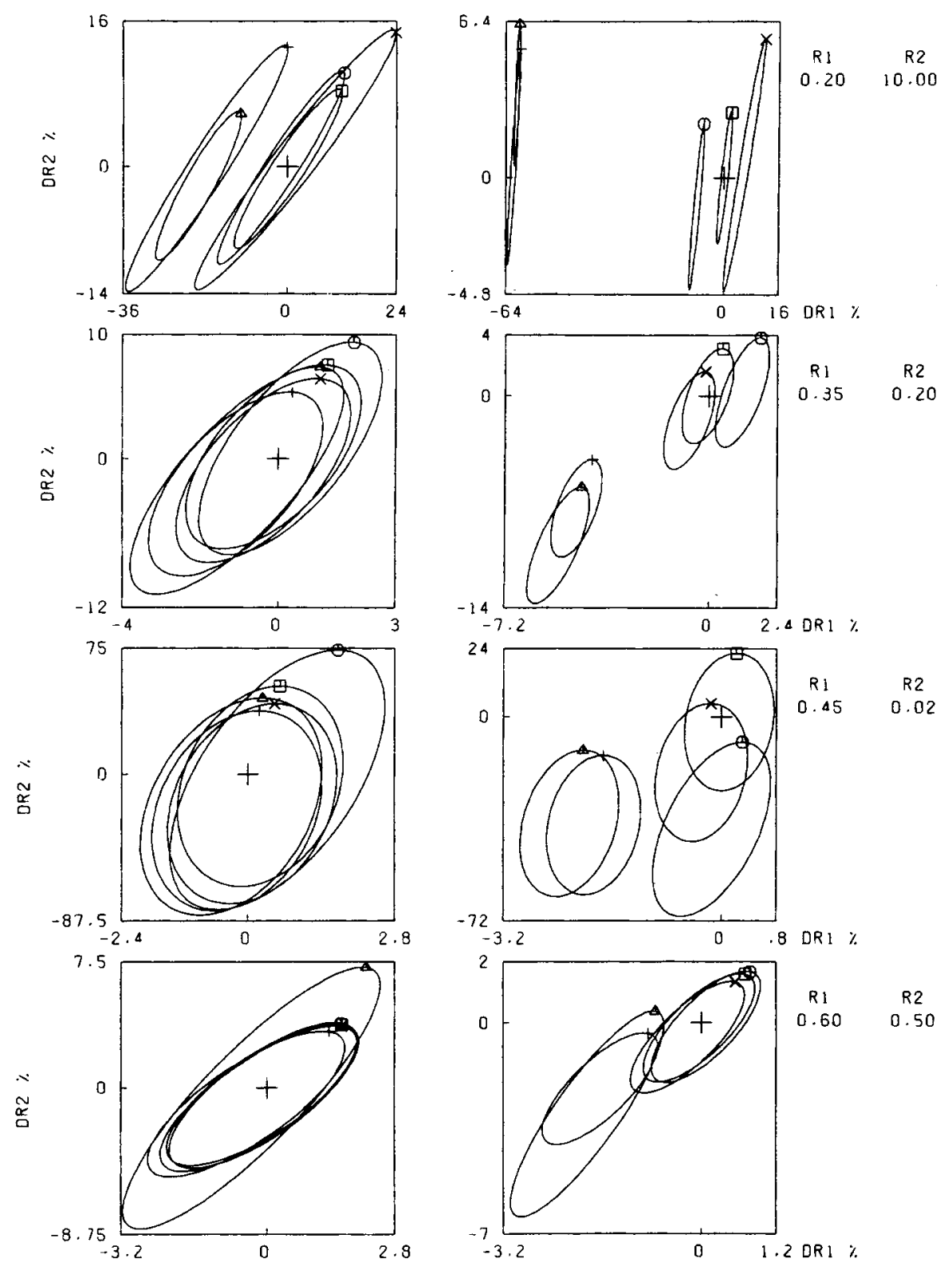

Fig. 2. $50 \%$ ellipsoids for methods VLG $(\square)$, WLS $(O)$, ALMA $(\triangle)$, KTL $(+)$, and KTH $(\times)$.

on the $r$-values calculated should be taken into account if calculation methods are compared.

\section{EFFECT OF APPROXIMATING MONOMER FEED RATIO}

The simple differential copolymer equation

$$
\frac{d\left[\mathrm{M}_{1}\right]}{d\left[\mathrm{M}_{2}\right]}=\frac{r_{1} q_{i}+1}{r_{2} / q_{i}+1}
$$



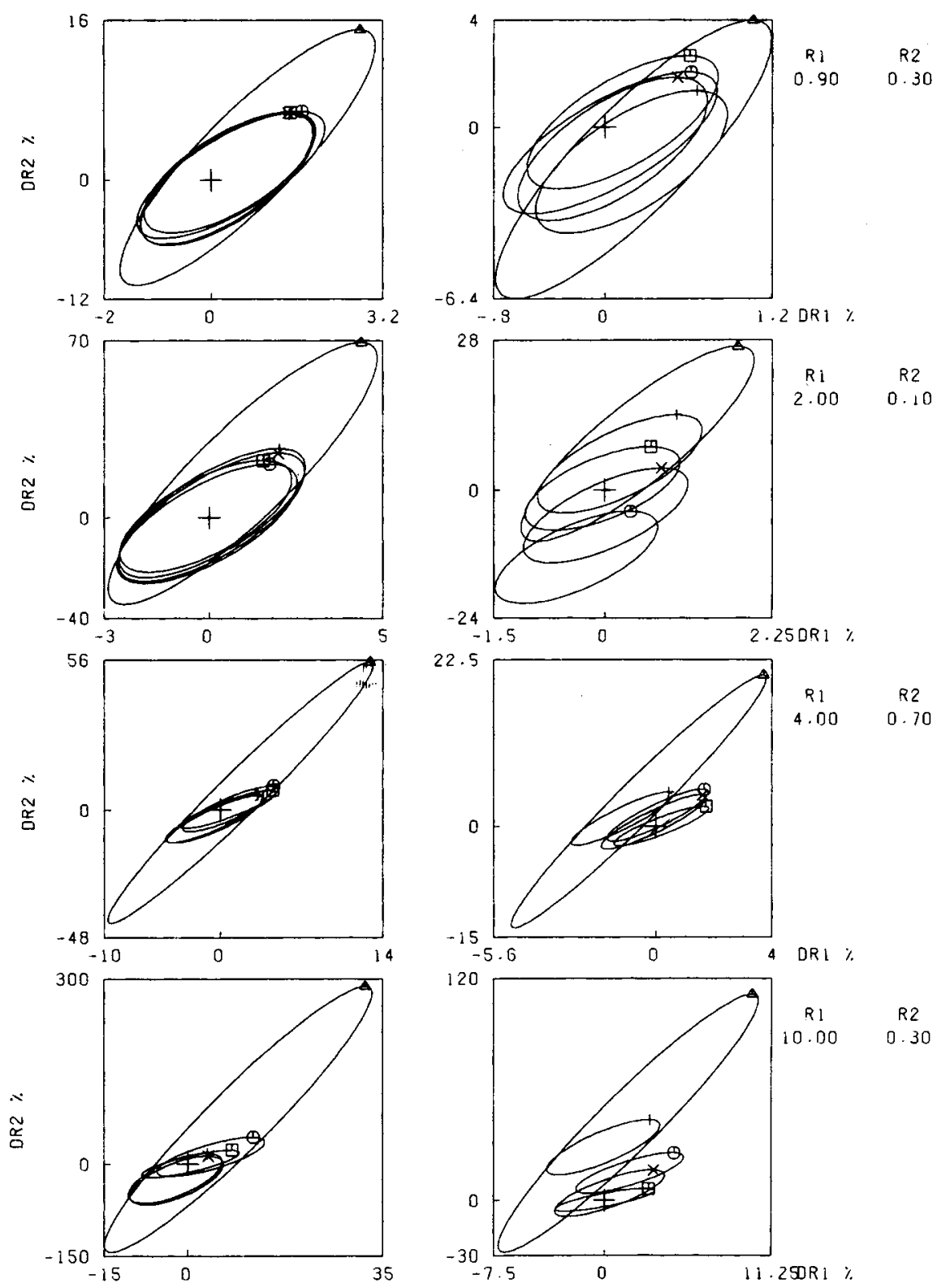

Fig. 3. 50\% ellipsoids for methods VLG (D), WLS $(O)$, ALMA $(\triangle)$, KTL $(+)$, and KTH $(\times)$.

where $q_{i}=$ instantaneous monomer feed ratio, requires $d \mathrm{M}_{1} / d \mathrm{M}_{2}$ to be measured instantaneously. Since this is not possible the reaction usually will be allowed to proceed until a chosen conversion is reached and the ratio $d \mathrm{M}_{1} / d \mathrm{M}_{2}$ is approximated by $\Delta \mathrm{M}_{1} / \Delta \mathrm{M}_{2}$ (copolymer composition). In general, the monomer feed ratio will be drifting as conversion increases and in most practical approaches either the initial monomer feed ratio $\left(q_{0}\right)$ or an average monomer feed ratio $q_{\mathrm{A}}$ (see eq. (2)) is introduced as an approximation of $q_{i}$. The effect of these approximations on the calculated 
$r$-values is investigated by simulation for the calculation methods ALMA, KETL, and WLS. In the case of approximation of $q_{i}$ by $q_{0}$, eqs. (3), (5), and (7) remain the same except that $q_{\mathrm{A}}$ is replaced by $q_{0}$.

The same series of "experiments" presented in Table I are simulated, but now only bias will be compared so the simulated ideal GLC peak areas are used to recalculate the $r$-values for each of the three methods and for $q_{i}=$ $q_{\mathrm{A}}$ and $q_{i}=q_{0}$. The deviations of the calculated $r$-values from the true values can be considered as the bias introduced by the approximation of $d \mathrm{M}_{1} / d \mathrm{M}_{2}=\Delta \mathrm{M}_{1} / \Delta \mathrm{M}_{2}$ and $q_{i}=q_{0}$ or $q_{i}=q_{\mathrm{A}}$. Note that the approximation $d \mathrm{M}_{1} / d \mathrm{M}_{2}=\Delta \mathrm{M}_{1} / \Delta \mathrm{M}_{2}$ is the same for both cases.

Table II shows the copolymer composition and $q_{\mathrm{A}}$ for $q_{0}=5$ and $q_{0}=$ 0.5 for all cases. In Table III the relative deviations defines as $(r-R) / R$ $\times 100(\%)$ are displayed, where $R$ is the true and $r$ is the calculated $r$-value.

Inspection of Tables II and III yields the following conclusions:

(1) The bias caused by approximating $q_{i}$ by $q_{\mathrm{A}}$ is in very good agreement with the bias that can graphically be determined in Figures 2 and 3 .

(2) The approximation of $q_{i}$ by $q_{0}$ instead of $q_{\mathrm{A}}$ is not recommended because a considerable bias is introduced even when conversion is small (20\%); if the conversion is chosen smaller bias will become smaller but so will precision (see Figs. 2 and 3 ).

TABLE II

Copolymer Composition and Average Monomer Feed Ratio for Experiments with Initial Feed Ratio $q_{0}=5$ and $q_{0}=0.5$ for All Cases

\begin{tabular}{|c|c|c|c|c|c|c|}
\hline \multirow[b]{2}{*}{$R_{1}$} & \multirow[b]{2}{*}{$R_{2}$} & \multirow{2}{*}{$\begin{array}{c}\text { Total } \\
\text { conversion } \\
(\%)\end{array}$} & \multicolumn{2}{|c|}{$\Delta \mathrm{M}_{1} / \Delta \mathrm{M}_{2}$} & \multicolumn{2}{|c|}{$q_{\mathrm{A}}$} \\
\hline & & & $q_{0}=\mathbf{5}$ & $q_{0}=0.5$ & $q_{0}=5$ & $q_{0}=.5$ \\
\hline \multirow[t]{2}{*}{0.2} & 10 & 20 & 1.02 & 0.06 & 7.93 & 0.59 \\
\hline & & 40 & 1.67 & 0.07 & 19.66 & 0.77 \\
\hline \multirow[t]{2}{*}{0.35} & 0.2 & 20 & 2.81 & 0.82 & 5.51 & 0.47 \\
\hline & & 40 & 3.03 & 0.79 & 6.45 & 0.43 \\
\hline \multirow[t]{2}{*}{0.45} & 0.02 & 20 & 3.37 & 1.15 & 5.31 & 0.45 \\
\hline & & 40 & 3.54 & 1.12 & 5.82 & 0.38 \\
\hline \multirow[t]{2}{*}{0.6} & 0.5 & 20 & 3.76 & 0.64 & 5.21 & 0.48 \\
\hline & & 40 & 3.91 & 0.62 & 5.52 & 0.47 \\
\hline \multirow[t]{2}{*}{0.9} & 0.3 & 20 & 5.17 & 0.86 & 4.98 & 0.47 \\
\hline & & 40 & 5.15 & 0.81 & 4.95 & 0.42 \\
\hline \multirow[t]{2}{*}{2} & 0.1 & 20 & 10.16 & 1.51 & 4.69 & 0.43 \\
\hline & & 40 & 9.45 & 1.32 & 4.34 & 0.36 \\
\hline \multirow[t]{2}{*}{4} & 0.7 & 20 & 16.70 & 1.09 & 4.57 & 0.45 \\
\hline & & 40 & 14.77 & 0.94 & 4.12 & 0.40 \\
\hline \multirow[t]{2}{*}{10} & 0.3 & 20 & 42.61 & 2.80 & 4.47 & 0.40 \\
\hline & & 40 & 36.44 & 1.85 & 3.92 & 0.32 \\
\hline
\end{tabular}




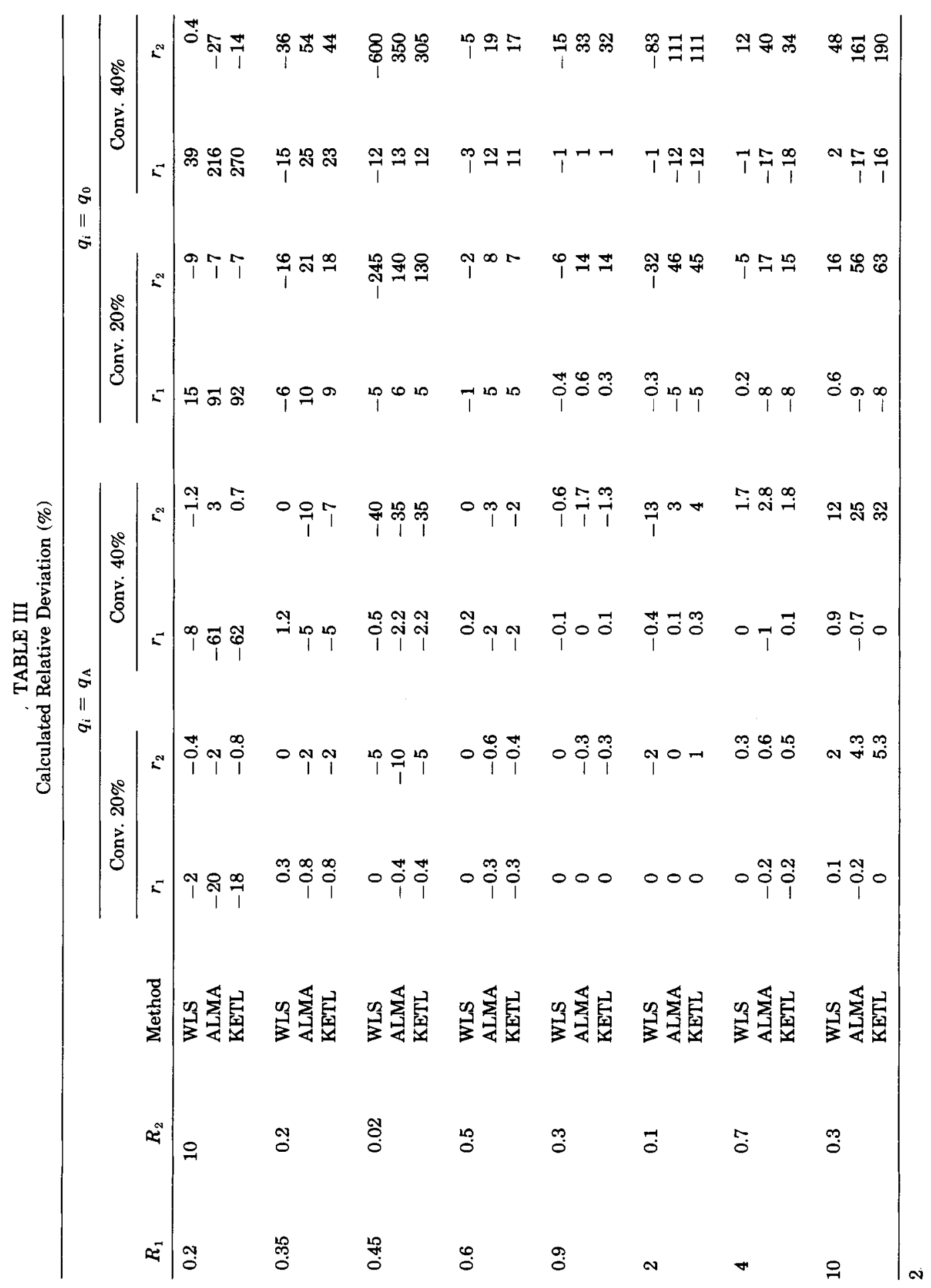


TABLE IV

Calculation Method KETL

\begin{tabular}{ccccc}
\hline & Reference & $q_{i}=q_{\mathrm{A}}$ & $q_{i}=q_{0}$ & \\
\hline$r_{1}$ & 0,22 & 0,21 & 0,40 & $+90 \%$ \\
$r_{2}$ & 1,25 & 1,29 & 1,19 & $-5 \%$ \\
\hline
\end{tabular}

$r$-Values of tert butyl acrylate/styrene/benzene $/ \mathrm{Bz}_{2} \mathrm{O}_{2} / 70 \%{ }^{\circ} \mathrm{C}$. Recalculation $r$-values according to KETL with $q_{i}=q_{\mathrm{A}}$, respectively $q_{1}=q_{0}$. Here it is also shown that approximation of $q_{i}$ by $q_{0}$ has a strongly negative effect on the reliability of determining $r$-values.

(3) In general WLS is less sensitive to bias introduced by the approximation of $q_{i}$ by $q_{0}$ or $q_{\mathrm{A}}$ than ALMA or KETL.

It is remarkable that even in the event of common $r$-values (e.g., $r_{1}=$ $0.9, r_{2}=0.3$, conversion $=20 \%$ ) the bias in $r_{2}$ for the methods ALMA and KETL is $14 \%$ due to the approximation $q_{i}=q_{0}$ although the monomer feed ratios show a small drift (see Table II).

To demonstrate the effect of approximating $q_{i}$ by $q_{0}$ instead of $q_{\mathrm{A}}$, data published by Cherkezyan et al. ${ }^{11}$ concerning the determination of $r$-values at high conversions (about 50\%) in the copolymerization of tert butyl acrylate with styrene were recalculated using the calculating method KETL with $q=q_{0}$ and $q=q_{\mathrm{A}}$. The results are shown in Table IV.

The authors thank Mr. H. Willemsen for the development of the software required to represent the data graphically.

\section{References}

1. T. Alfrey, Jr. and G. Goldfinger, J. Chem. Phys., 12, 205 (1944).

2. F. R. Mayo and F. M. Lewis, J. Am. Chem. Soc., 66, 1594 (1944).

3. H. Patino-Leal, P. M. Reilly, and H. F. O'Driscoll, J. Polym. Sci. Polym. Lett. Ed., 18, 219 (1980).

4. R. Van der Meer, H. N. Linssen, and A. L. German, J. Polym. Sci. Polym. Chem. Ed., 16, 2915 (1978).

5. M. Fineman and S. D. Ross, J. Polym. Sci., 5, 259 (1950).

6. F. Tüdös, T. Kelen, T. Földes-Berezsnich, and B. Turcsanyi, J. Macromol. Sci. Chem. A, 10(8), 1513 (1976).

7. T. Kelen, F. Tüdös, and B. Turcsanyi, Polym. Bull., 2, 71 (1980).

8. D. G. Watts, H. N. Linssen, and Y. Schrijver, J. Polym. Sci. Polym. Chem. Ed., 18, 1285 (1980).

9. H. N. Linssen, Nonlinear regression with nuisance parameters: An algorithm to estimate the parameters, in Proceedings, 1st European Meeting of Statisticians, Grenoble, 1976, NorthHolland, Amsterdam, 1977.

10. R. C. McFarlane, P. M. Reilly, and K. F. O’Driscoll, J. Polym. Sci. Polym. Chem. Ed., 18, 251 (1980).

11. V. O. Cherkezyan, A. D. Litmanovich, T. N. Khromova, and A. Yu. Koshevnik, Vysokomol. Soedin. Ser. B, 24(3), 237 (1982).

Received February 14, 1984

Accepted March 23, 1984 